\title{
INDIVIDUAL SUSCEPTIBILITY TO NOISE-INDUCED HEARING LOSS: CHOOSING AN OPTIMAL METHOD OF RETROSPECTIVE CLASSIFICATION OF WORKERS INTO NOISE-SUSCEPTIBLE AND NOISE-RESISTANT GROUPS
}

\author{
MARIOLA ŚLIWIŃSKA-KOWALSKA ${ }^{1,2}$, ADAM DUDAREWICZ ${ }^{2}$, PIOTR KOTYŁO ${ }^{1}$, \\ EWA ZAMYSŁOWSKA-SZMYTKE ${ }^{1}$, MALGORZATA PAWLACZYK-ŁUSZCZYŃSKA ${ }^{2}$, \\ and ANNA GAJDA-SZADKOWSKA ${ }^{1}$
}

${ }^{1}$ Department of Audiology and Phoniatrics

${ }^{2}$ Department of Physical Hazards

Nofer Institute of Occupational Medicine

Łódź, Poland

\begin{abstract}
Objectives: Individual susceptibility to noise-induced hearing loss (NIHL) depends on the interaction between intrinsic and environmental factors. To proceed with the study on NIHL susceptibility genes an appropriate selection of workers susceptible and resistant to noise is crucial. The aim of the study was to compare four different methods of subject classification by the susceptibility to NIHL in a group of 949 workers of an electric power plant exposed to steady-state noise at the workplace. Materials and Methods: One method based the classification of the workers on the international reference standard ISO 1999:1990; from the entire group of workers, 10\% of the subjects with the worst hearing thresholds (HT) in the model were categorized as susceptible to NIHL, whereas $10 \%$ of the subjects with the best HT were categorized as resistant to noise. According to three other methods, the entire group of workers was first divided into subgroups by age, duration of employment and the level of noise, and then $10 \%$ of the subjects at each HT extreme were selected. Results: The first classification allowed to achieve an excellent separation between HT of the susceptible and resistant subgroups. The susceptible subgroup was significantly younger than the resistant one, showed a shorter duration of employment and a lower level of noise exposure, which is in line with the definition of increased vulnerability to NIHL. The three other methods produced poorer separation of HT with smaller or no gap between HT values in subgroups. Conclusions: The selection of subjects from the entire worker population of a given industry based on the ISO 1999:1990 standard can be regarded as the most reliable method of classification of noise-susceptible and noise-resistant workers to be used in the future genetic studies on NIHL susceptibility genes.
\end{abstract}

Key words:

ISO 1999:1990 standard, NIHL modeling, Hearing thresholds

\section{INTRODUCTION}

Hearing loss induced by occupational and leisure noise exposure is the second most frequent cause of acquired sensorineural hearing loss in the adult population. It has been estimated that around 30 million people are exposed to unsafe noise levels at work [1].

Most of the countries adopted the A-filter-weighted sound pressure level system and the equal energy principle for

\footnotetext{
This study was supported by the State Scientific Committee for Research (Grant No. PB 0911/P05/2004/26) and the 6th European Framework Project under the Marie Curie Host Fellowship for the Transfer of Knowledge "NoiseHear" (Contract No. MTKD-CT-2004-003137).

Received: July 21, 2006. Accepted: September 26, 2006.

Address reprint requests to Prof. M. Śliwińska-Kowalska, MD, PhD, Department of Audiology and Phoniatrics, Nofer Institute of Occupational Medicine, św. Teresy 8 , 91-348 Łódź, Poland (e-mail: marsliw@imp.lodz.pl).
} 
assessing and limiting noise exposure [2]. Noise exposure levels related to an 8-h working day (or a 40-h working week) $\left(\mathrm{L}_{\mathrm{Ex}, 8 \mathrm{~h}}\right)$, exceeding the occupational exposure limit (OEL) of $85 \mathrm{~dB}(\mathrm{~A})$, are considered to be dangerous to the auditory system [3]. Statistically, sound exposure levels between $80-85 \mathrm{~dB}(\mathrm{~A})$ have only a small influence on hearing over the long term; however, they are still capable of inducing measurable hearing threshold (HT) shifts in the high frequency range in susceptible subjects [3].

Noise-induced hearing loss (NIHL) is a sensorineural hearing impairment that develops over the years of exposure to noise. It is predominantly noted in the high frequency region with typical notch at 4-6 kHz. Although in principle it is supposed to be symmetrical, the left ear is somehow more vulnerable and develops more hearing loss than the right ear [4]. A possible explanation for this phenomenon is the human laterality (a majority of people are right-handed).

Individual susceptibility (or vulnerability) to noise along with the degree of hearing loss varies greatly among people [3], which means that after the same exposure to noise, some persons develop substantial hearing loss, whereas others develop little or no hearing loss at all. Another definition of an increased vulnerability towards noise says that vulnerable individuals experience acoustic trauma below noise exposure levels classified as being dangerous to hearing.

Noise-induced HT shift depends on the interaction between intrinsic and environmental factors [5]. Besides well known environmental factors contributing to occupational NIHL, such as the equivalent level of exposure to noise $\left(\mathrm{L}_{\text {eqA }}\right)$ and years of exposure, some others may play a role. They include, e.g., impulsiveness of noise (impulse noise is more harmful than steady-state noise at the same equivalent level) [6]; exposure paradigm (breaks in noise exposure allow for the recovery); noise exposures beyond workplace (leisure noise, military noise) $[5,7,8]$; occupational exposures to certain chemicals (organic solvents, asphyxiants, heavy metals and pesticides) [5,9]; co-exposure to noise and vibration [5]; ototoxic drugs (aminoglycosides, cis-platin and others), temperature and smoking [10].
Several individual (biological) factors have also been studied in their role to aggravate NIHL [11]. An association has been found between NIHL and elevated blood pressure (risk factor), cholesterol level (risk factor), gender (women are less susceptible), age (increasing effect of presbyacusis with age), and eye color (blue-eyed individuals seem to be more susceptible to NIHL than subjects with greater melanin content in their eyes) [8,12]. In contrast to environmental factors, very little is currently known about the genetic basis of NIHL. To proceed with such studies, large populations of NIHL-susceptible and NIHL-resistant subjects have to be screened for candidate-gene polymorphisms.

In 1990, the International Organization for Standardization (ISO) published the mathematical model permitting to predict permanent hearing threshold shift (PTS) after a given occupational noise exposure (ISO 1999:1990) [13]. The ISO model uses three parameters: age, gender and exposure to noise ( $\mathrm{L}_{\mathrm{ExA}}$ and years of exposure) in PTS evaluation. Using these parameters, the distribution of NIHL can be calculated. The variation is large, e.g., for men working at $100 \mathrm{~dB}(\mathrm{~A})$ noise for 30 years, the difference between $10 \%$ and $90 \%$ percentile of hearing loss is $60 \mathrm{~dB}$ HL [11]. In other words, after 30 years of exposure to noise at the level of $100 \mathrm{~dB}(\mathrm{~A})$, the difference in hearing threshold shift between $10 \%$ of the most susceptible and $10 \%$ of the most resistant subjects would be $60 \mathrm{~dB}$ HL. The ISO model, although being not perfect, is at present the most widely used method for classification of noise-susceptible and noise-resistant subjects $[14,15]$.

The aim of this study was to assess the reliability of different methods of retrospective classification of subjects by their susceptibility to NIHL and compare them to the ISO model of NIHL prediction.

\section{MATERIALS AND METHODS}

The study group comprised 949 male workers of an electric power plant station, exposed to noise at workplace, aged 20-67 years (mean, $41.7 \pm 7.9$ years). Duration of exposure (tenure) ranged from 1 to 30 years (mean, 
Table 1. Characteristics of the study population

\begin{tabular}{|c|c|c|c|c|c|}
\hline $\begin{array}{c}\text { No. } \\
\text { of workers }\end{array}$ & Gender & $\begin{array}{l}\text { Age } \\
\text { (years) } \\
\pm \mathrm{SD}^{*}\end{array}$ & $\begin{array}{l}\text { Exposure to noise } \\
\text { (years) } \\
\pm \mathrm{SD}^{*}\end{array}$ & $\begin{array}{l}\text { Level of noise** } \\
\left(\mathrm{L}_{\mathrm{Ex}} \text { in } \mathrm{dB}(\mathrm{A})\right) \\
\quad \pm \mathrm{SD}^{*}\end{array}$ & $\begin{array}{c}\text { Level } \\
\text { of noise } \\
\text { (median in } \mathrm{dB}(\mathrm{A}) \text { ) }\end{array}$ \\
\hline \multirow[t]{2}{*}{949} & Male & Mean $41.7 \pm 7.9$ & Mean $17.0 \pm 4.7$ & Mean $84.5 \pm 3.0$ & $\mathrm{Q} 50=85.0$ \\
\hline & & Range 20-67 & Range 1-30 & Range 68.3-90.3 & $\mathrm{Q} 25^{* * *}=83.1 \mathrm{Q} 75^{* * *}=87.2$ \\
\hline
\end{tabular}

$17.0 \pm 4.7$ years). The inclusion criteria were as follows: at least 1 year of exposure to noise, no history of middle ear diseases, no history of causes of hearing impairment other than noise exposure, no air-borne gap in pure-tone audiometry, no more than $40 \mathrm{~dB}$ difference between hearing thresholds in the right and the left ear at 4 and $6 \mathrm{kHz}$. The characteristics of the study group are presented in Table 1.

The sanitary inspection records and medical files were explored. The following data were stored in the database: age, gender, department, current job post in the factory, noise exposure levels at every single job post over a worker's entire time of employment in this electric power station (up to 8 job posts in some cases), cigarette smoking (years and numbers), alcohol drinking, head injury, history of acoustic trauma, dizziness, vertigo and tinnitus, blood pressure, weight, and heigth. All pure-tone audiometry results available in the medical file were introduced into the database; the latter was used in the NIHL modeling and workers' classification. Hearing thresholds were measured in a sound-proof room by the local occupational medicine staff using an ascending-descending technique in $5-\mathrm{dB}$ steps (ISO 8253-1) [16].

\section{Assessment of exposure to noise}

Since the employees were exposed to different noise levels during different employment periods, the noise exposure level averaged over each worker's total time of exposure was calculated using the following formula:

$$
\overline{\mathrm{L}_{\mathrm{Ex}, 8 \mathrm{~h}}}=10 \lg \left(\frac{1}{\sum_{\mathrm{i}=1}^{\mathrm{N}} \mathrm{T}_{\mathrm{i}}} \sum_{\mathrm{i}=1}^{\mathrm{N}} \mathrm{T}_{\mathrm{i}} \cdot 10^{0,1 \mathrm{~L}_{\mathrm{Ex}_{\mathrm{i}}}}\right)
$$

where:

$\mathrm{N}-$ is the total number of various time intervals/workplaces/jobs;

$\mathrm{L}_{\text {Exi }}$ - is the equivalent continuous A-weighted sound pressure level normalized to a nominal 8-h working day in the time interval/workplace/job i, in $\mathrm{dB}$;

$\mathrm{T}_{\mathrm{i}}-$ is the duration of time interval $\mathrm{i}$, in years.

The averaged individual levels of noise exposure ranged from 68.3 to $90.3 \mathrm{~dB}(\mathrm{~A})$; mean $\mathrm{L}_{\mathrm{Ex}, 8 \mathrm{~h}}=84.5 \pm 3.0 \mathrm{~dB}(\mathrm{~A})$.

\section{Classification of workers into noise-susceptible and noise-resistant groups}

The workers were classified as susceptible or resistant to NIHL according to the following principles:

1) $10 \%$ of workers with the poorest hearing thresholds were categorized as susceptible to NIHL, whereas $10 \%$ with the best hearing thresholds were categorized as resistant to noise;

2) since the frequencies of 4 and $6 \mathrm{kHz}$ are the most sensitive to noise trauma and the left ear was shown to be more vulnerable than the right ear, the categorization was based on HT in the left ear at 4 and $6 \mathrm{kHz}$; hearing thresholds of all persons were plotted on the Cartesian co-ordinate system (axis X - HT at $4 \mathrm{kHz}$, axis $\mathrm{Y}$ - HT at $6 \mathrm{kHz}$ ) and $10 \%$ of individuals (points) were cut off at each extreme (Fig. 1);

3) in classification I, based on the ISO 1999:1990 model, absolute hearing threshold values were converted to so called "relative standardized scale", i.e., they were shown as the differences between real hearing thresholds (measured on the last worker's audiometric exam) and hearing thresholds predicted from the ISO 1999:1990 model; in all other classifications (II, III and IV) absolute values of hearing thresholds were used. 


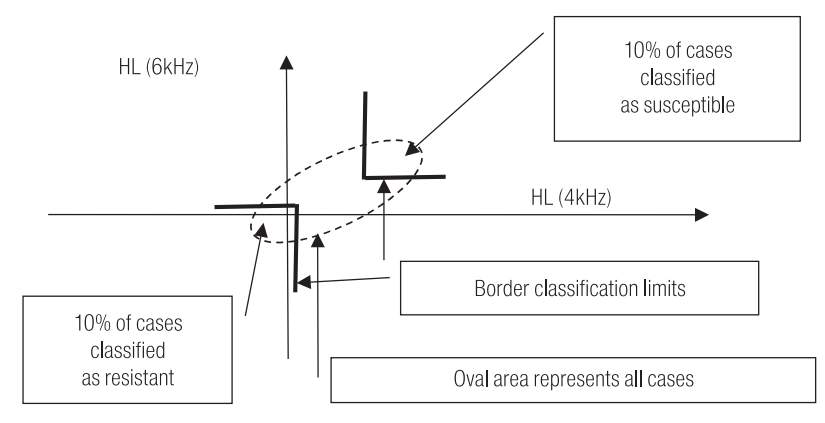

Fig. 1. Schematic method of selecting $10 \%$ of noise-susceptible and $10 \%$ of noise-resistant workers.

\section{Four approaches to workers' dichotomization were used:}

Classification I was performed in the whole group of workers using the ISO 1999:1990 model and the relative standardized scale of hearing thresholds ("gold standard method").

To minimize the effect of age, classification II was performed in ten age subgroups with the similar number of subjects (ranging from 53 to 139). In each subgroup, 10\% of persons with the poorest absolute hearing thresholds and $10 \%$ with the best absolute hearing thresholds were selected. Then, to compare the results of classifications I and II, hearing threshold absolute values were converted to the relative standardized scale.

To minimize the effect of both age and exposure level in classification III, the entire group of workers was divided into three age subgroups (35 years or less, 36-50 years, and over 50 years) and two noise exposure level subgroups ( $85 \mathrm{~dB}-\mathrm{A}$ or below, and over 85 to $91 \mathrm{~dB}-\mathrm{A}$ ). In total, six subgroups were established ( 3 age $\bullet 2$ noise level subgroups). The number of workers in each subgroup ranged from 80 to 390. Like in classification II, $10 \%$ of workers in each subgroup at each extreme - with the poorest absolute hearing thresholds and the best absolute hearing thresholds - were selected. Then, to compare the obtained results with those of classification I, the absolute values of hearing thresholds were converted to the relative standardized scale.

To minimize the effect of all three variables: age, noise exposure level and duration of employment, in classification IV, the entire group of workers was divided into three age subgroups ( 35 years or below, 36-50 years, and over 50 years), two exposure level subgroups ( $85 \mathrm{~dB}$-A or below, and over 85 to $91 \mathrm{~dB}-\mathrm{A})$, and three employment duration subgroups
(10 years or below, 11-20 years, and over 20 years). The number of subgroups was 18 ( 3 age $\bullet 2$ noise $\cdot 3$ employment duration subgroups). The number of subjects in each subgroup ranged from 60 to 280 . The following procedures were the same as in classifications II and III.

\section{Standardized hearing thresholds scale}

The ISO 1999:1990 model assumes that hearing threshold level (HTL) of occupationally noise-exposed population is a combination of hearing threshold level associated with age (HTLA) and noise-induced permanent threshold shift (NIPTS); HTL is calculated using the following empirical formula (ISO 1999:1990) [13]:

$$
\begin{gathered}
\mathrm{HTL}=\mathrm{HTLA}+\mathrm{NIPTS}-(\mathrm{HTLA} \cdot \mathrm{NIPTS}) / 120(2) \\
{[\text { in decibels }]}
\end{gathered}
$$

Thus, the HTLA is a function of gender and age (ISO 7029) [17].

For the purpose of this study, we introduced so called "standardized hearing threshold scale" based on the following assumptions:

1) the ISO 1999:1990 model reliably predicts the distribution of HTL in noise-exposed population and quantitative dependencies of HTL on age and exposure to noise; 2) the difference $(\Delta)$ between actual individual HTL (HTLm) and median HTL $\left(\mathrm{HTL}_{0.50}\right)$ in the population of the same age and noise exposure is a measure describing the state of the auditory system of a given person.

The delta is expressed by subtracting $\mathrm{HTL}_{0.50}$ from $\mathrm{HTL}_{\mathrm{m}}$

$$
\Delta=\mathrm{HTL}_{\mathrm{m}}-\mathrm{HTL}_{0.50}
$$

This variable allows to compare HTL of individuals within the population of the same gender, age, and noise exposure. Because the widths of the predicted distribution change with changing exposure to noise and age, the widths of the distribution were applied to standardization according to the following formulas:

$$
\begin{gathered}
\Delta_{\text {stand }}=1.282\left(\mathrm{HTL}_{\mathrm{m}}-\mathrm{HTL}_{0.50}\right) /\left(\mathrm{HTL}_{0.10}-\mathrm{HTL}_{0.50}\right) \\
\text { for } \mathrm{HTL}_{\mathrm{m}} \geq \mathrm{HTL}_{0.50} \\
\Delta_{\text {stand }}=1.282\left(\mathrm{HTL}_{\mathrm{m}}-\mathrm{HTL}_{0.50}\right) /\left(\mathrm{HTL}_{0.50}-\mathrm{HTL}_{0.90}\right) \\
\text { for } \mathrm{HTL}_{\mathrm{m}}<\mathrm{HTL}_{0.50}
\end{gathered}
$$

This procedure is similar to the standardization in case of the normal distribution, but the predicted HTL distribu- 
tion consists of two halves of Gaussian distributions of different widths; thus different functions were applied to standardize $\mathrm{HTL}_{\mathrm{m}}$ of values above and below the expected $\mathrm{HTL}_{0.50^{\circ}}$ The constant 1.282 corresponds with 0.10 and 0.90 fractiles of the standardized Gaussian distribution, and it could be changed if one applies to fractiles other than 0.10 and 0.90 in the above equations (4) and (5).

The $\Delta$ value is expressed in units equal to standard deviation of normal distribution (standard units). The highest positive values of HTL in standard units indicate the persons who are most susceptible to noise, while the lowest negative values of HTL in standard units indicate those who are most resistant to noise.

In this way, one can obtain the scale of hearing state that combines information on hearing threshold level, noise exposure and age, whereby it is possible to make direct comparison between individuals originated from different populations without the necessity of performing preliminary case classifications with respect to age (as in classification II) or age and noise exposure (as in classifications III and IV).

\section{Statistical analysis}

Statistical analyses were completed using STATISTICA 6.1 (StatSoft, Inc. 1984-2004).

The distribution of age, duration of employment and noise exposure level referred to an 8-h working day in the susceptible and resistant groups was compared by the MannWhitney $U$ test. The analyses were performed assuming a level of statistical significance of $p=0.05$.

\section{Ethics}

The study protocol was approved by the Regional Bioethical Committee at the Nofer Institute of Occupational Medicine in Łódź.

\section{RESULTS}

Table 2 shows mean and median values of age, duration of employment, noise exposure level and hearing levels at 4 and $6 \mathrm{kHz}$ in the NIHL-susceptible and NIHL-resistant persons for all the methods of subject classification (I, II, III and IV).

\section{Classification I}

In classification I when the dichotomization was made in the entire group of workers, a significant difference between groups regarding age, duration of employment and noise exposure was observed (Table 2). The workers classified as resistant to noise were on average about 4 years older than those susceptible to noise. They also showed a longer time of exposure (almost 2 years on average) and a slightly higher noise exposure level (Table 2). The age distribution indicated a substantial representation of young workers, aged below 40 years, in the noise-susceptible subgroup, while there were few of them in the resistant subgroup (Fig. 2a). The distribution of employment duration showed a higher representation of the employees with shorter duration of employment in the sensitive subgroup (Fig. 2b), while the distribution of noise exposure levels showed a shift toward higher values in the resistant subgroup (Fig. 2c). The scatterplot of hearing thresholds at 4 and $6 \mathrm{kHz}$ showed an ex-
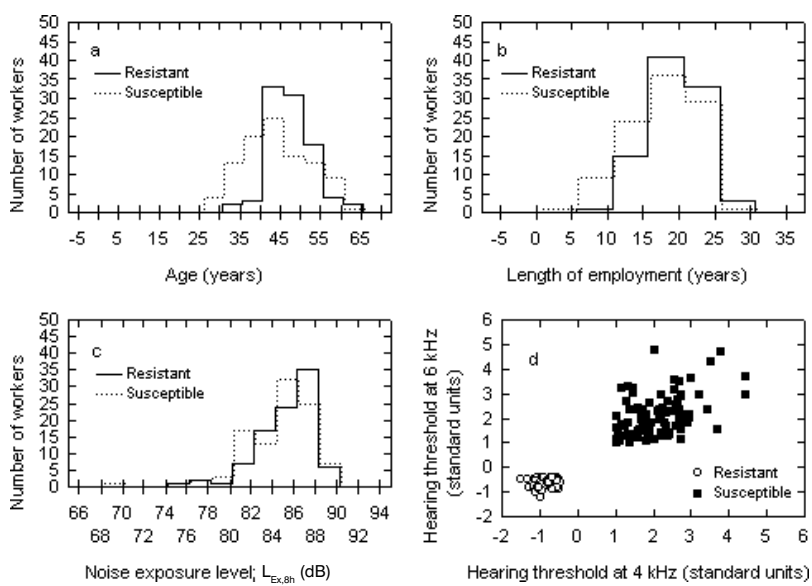

(a) Age distribution in the noise-susceptible and noise-resistant subgroups: there is a significant age difference in both subgroups $(\mathrm{p}<0.0001)$. Note more younger subjects (aged under 40 years) in the susceptible subgroup; (b) The duration of employment in the noise-susceptible and noise-resistant subgroups. There is a significant difference in the duration of employment between two subgroups $(p=0.03)$. Note more subjects with shorter duration of employment in the susceptible subgroup; (c) The noise exposure level (normalized to 8-h working day, averaged over the total exposure time) in the noise-susceptible and noise-resistant subgroups. The susceptible subgroup was exposed to significantly lower noise exposure levels $(p=0.03)$; (d) Standardized hearing thresholds in the noise-susceptible and noise-resistant subgroup. Note a very good (more than 1 standard unit) hearing thresholds separation of both subgroups.

Fig. 2. Classification I - the entire group of workers. 
Table 2. Mean and median values of age, duration of employment, noise exposure level and hearing levels at 4 and $6 \mathrm{kHz}$ in the NIHL-susceptible and NIHL-resistant individuals for all methods of workers' classification

\begin{tabular}{|c|c|c|c|c|c|c|}
\hline Classification & Parameter & $\begin{array}{l}\text { Age } \\
\text { (years) }\end{array}$ & $\begin{array}{c}\text { Duration of } \\
\text { employment (years) }\end{array}$ & $\begin{array}{c}\text { Exposure } \\
\mathrm{L}_{\mathrm{Ex}, 8 \mathrm{~h}}^{*}(\mathrm{dBA})\end{array}$ & $\begin{array}{l}\text { Hearing level 4kHz } \\
\text { (standard units) }\end{array}$ & $\begin{array}{c}\text { Hearing level } \\
6 \mathrm{kHz} \\
\text { (standard units) }\end{array}$ \\
\hline \multicolumn{7}{|l|}{ Classification I } \\
\hline \multirow[t]{3}{*}{ Susceptible $(\mathrm{n}=94)$} & Mean & 43.5 & 17.4 & 84.3 & 2.150 & 2.128 \\
\hline & Median & 43.0 & 18.0 & 84.7 & 2.007 & 1.810 \\
\hline & $\mathrm{SD}$ & 8.0 & 5.0 & 3.1 & 0.883 & 1.078 \\
\hline \multirow[t]{3}{*}{ Resistant (n = 93) } & Mean & 47.4 & 19.2 & 85.1 & -0.681 & -0.417 \\
\hline & Median & 47.0 & 20.0 & 85.8 & -0.700 & -0.473 \\
\hline & SD & 5.4 & 3.8 & 2.7 & 0.438 & 0.495 \\
\hline Difference** & p-level & $<0.0001$ & 0.0346 & 0.0261 & & \\
\hline \multicolumn{7}{|l|}{ Classification II } \\
\hline \multirow{3}{*}{ Susceptible $(\mathrm{n}=92)$} & Mean & 41.6 & 16.3 & 84.0 & 2.371 & 2.318 \\
\hline & Median & 41.5 & 18.0 & 84.4 & 2.324 & 2.068 \\
\hline & SD & 7.6 & 5.3 & 3.1 & 0.944 & 1.178 \\
\hline \multirow[t]{3}{*}{ Resistant $(\mathrm{n}=96)$} & Mean & 42.0 & 18.1 & 86.1 & -0.504 & -0.300 \\
\hline & Median & 41.0 & 17.0 & 86.8 & -0.485 & -0.328 \\
\hline & SD & 8.0 & 4.0 & 2.1 & 0.326 & 0.321 \\
\hline Difference** & p-level & 0.8396 & 0.0795 & $<0.0001$ & & \\
\hline \multicolumn{7}{|l|}{ Classification III } \\
\hline \multirow[t]{3}{*}{ Susceptible $(n=94)$} & Mean & 42.7 & 17.4 & 84.8 & 2.220 & 2.316 \\
\hline & Median & 43.0 & 21.0 & 86.8 & 2.165 & 2.042 \\
\hline & $\mathrm{SD}$ & 7.6 & 4.8 & 2.9 & 1.044 & 1.227 \\
\hline \multirow[t]{3}{*}{ Resistant (n = 92) } & Mean & 40.9 & 17.3 & 85.0 & -0.374 & -0.204 \\
\hline & Median & 42.0 & 17.0 & 85.0 & -0.403 & -0.265 \\
\hline & SD & 7.3 & 4.9 & 2.4 & 0.443 & 0.415 \\
\hline Difference $^{* *}$ & p-level & 0.2014 & 0.9056 & 0.7212 & & \\
\hline \multicolumn{7}{|l|}{ Classification IV } \\
\hline \multirow[t]{3}{*}{ Susceptible $(\mathrm{n}=90)$} & mean & 41.4 & 17.1 & 84.4 & 2.244 & 2.187 \\
\hline & median & 41.0 & 18.0 & 85.0 & 2.139 & 2.013 \\
\hline & SD & 7.8 & 4.7 & 3.0 & 1.039 & 1.045 \\
\hline \multirow[t]{3}{*}{ Resistant (n = 90) } & mean & 44.3 & 17.6 & 85.2 & -0.513 & -0.340 \\
\hline & median & 45.0 & 18.0 & 85.1 & -0.524 & -0.367 \\
\hline & SD & 7.4 & 4.1 & 2.4 & 0.355 & 0.339 \\
\hline Difference** & p-level & 0.0028 & 0.6389 & 0.1210 & & \\
\hline
\end{tabular}

* Noise exposure level normalized to 8-h working day averaged over total exposure time;

** Mann-Whitney U test;

SD - standard deviation

cellent separation in values of both groups (Fig. 2d). In the susceptible group, all HTL values were at or above 1 standard unit at both frequencies, while in the resistant group they were below 0 standard unit. No overlapping hearing thresholds were evidenced.

\section{Classification II}

When the dichotomization was made in ten age subgroups, apparently no age and no tenure differences between susceptible and resistant groups were found (Table 2), and age distribution was very similar in both 

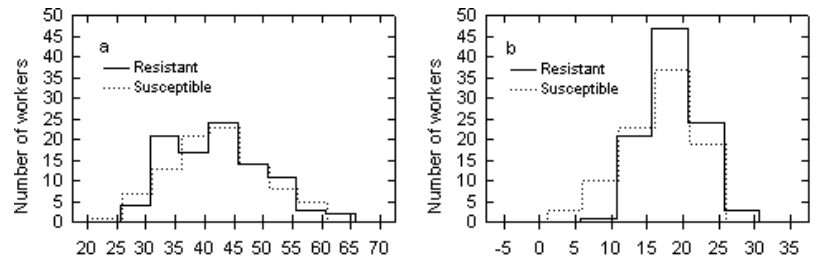

Age (years)
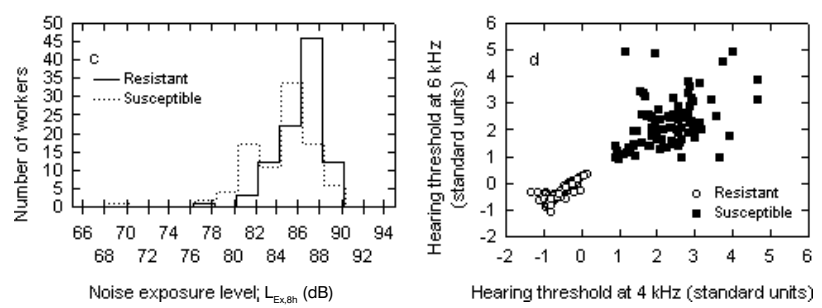

a) Age distribution in the noise-susceptible and noise-resistant subgroups. There are no differences in the mean age between two subgroups ( $p=0.84)$; $b$ ) The duration of employment in the noisesusceptible and noise-resistant subgroups. There are no differences in the duration of employment between two subgroups $(\mathrm{p}=0.08)$; c) The noise exposure level (normalized to 8-h working day, averaged over total exposure time) in the noise-susceptible and noise-resistant subgroups. The susceptible subgroup was exposed to significantly lower noise levels $(\mathrm{p}<0.0001)$; d) Standardized hearing thresholds in the noise-susceptible and noise-resistant subgroups. Note a poorer hearing thresholds separation of both subgroups than in classification I (less than 1 standard unit).

Fig. 3. Classification II - ten age subgroups.

subgroups (Fig. 3, a and b). The exposure noise level was on average almost $2 \mathrm{~dB}$ higher in the resistant than in the susceptible group (Table 2, Fig. 3c).

The scatterplot of hearing thresholds at 4 and $6 \mathrm{kHz}$ showed that the segregation of HTLs was poorer as compared to classification I. In several cases, less than 1 standard unit gap was noticed between HTLs of both groups (Fig. 3d).

\section{Classification III}

When the dichotomization was made in six subgroups accounting for two variables (age and noise exposure level), neither in these variables nor in duration of employment, the in-between subgroups differences were found (Table 2 and Fig. 4, a, b, and c). The scatterplot of hearing thresholds at 4 and $6 \mathrm{kHz}$ showed very poor segregation of $\mathrm{HL}$ values, with no gap between noise-susceptible and noiseresistant groups and several cases with overlapping hearing thresholds (Fig. 4d).
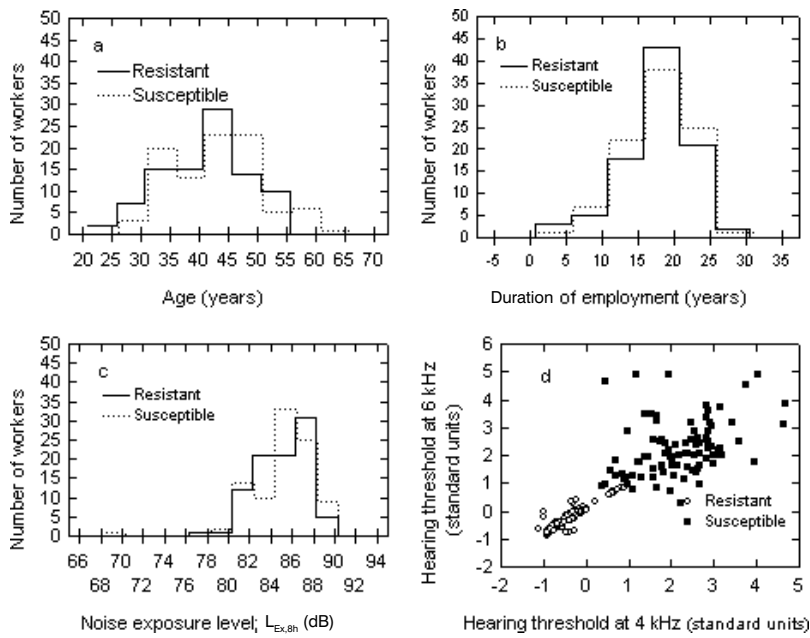

a) Age distribution in the noise-susceptible and noise resistant subgroups. There is no difference in the age between two subgroups $(p=0.2)$; $b)$ The duration of employment in the noise-susceptible and noise-resistant subgroups. There is no difference in the duration of employment between two subgroups $(p=0.9)$; $)$ The noise exposure level (normalized to 8-h working day, averaged over total exposure time) in the noise-susceptible and noise-resistant subgroups. There is no difference in the noise exposure level between two subgroups $(p=0.7212) ; d)$ Standardized hearing thresholds in the noise-susceptible and noise-resistant subgroups. Note a poor separation of hearing thresholds in both subgroups (with no gap between the susceptible and resistant workers and several overlapping hearing threshold values).

Fig. 4. Classification III - six subgroups divided by age and noise exposure level.

\section{Classification IV}

When the dichotomization was made in 18 subgroups accounting for three variables (age, duration of employment and noise exposure), there were no differences in the latter variables between groups; however, the difference in mean age was still present (Table 2 and Fig. 5, a, b, and c). The resistant group was on average over 3 years older than the susceptible group (Table 2, Fig. 5a). The segregation of HTL values was poor in classification IV, with no gap between the susceptible and resistant workers (Fig. 5d).

\section{Audiometric hearing thresholds}

The median values of hearing thresholds in the NIHL-susceptible and NIHL-resistant subgroups in respect of hearing thresholds predicted with the ISO 1999:1990 model are presented in Fig. 6. Regardless of the method of classification used, the audiometric curves of susceptible subgroups at the frequencies above $3 \mathrm{kHz}$ lay below the 0.1 decile curve predicted for the entire population of workers with 

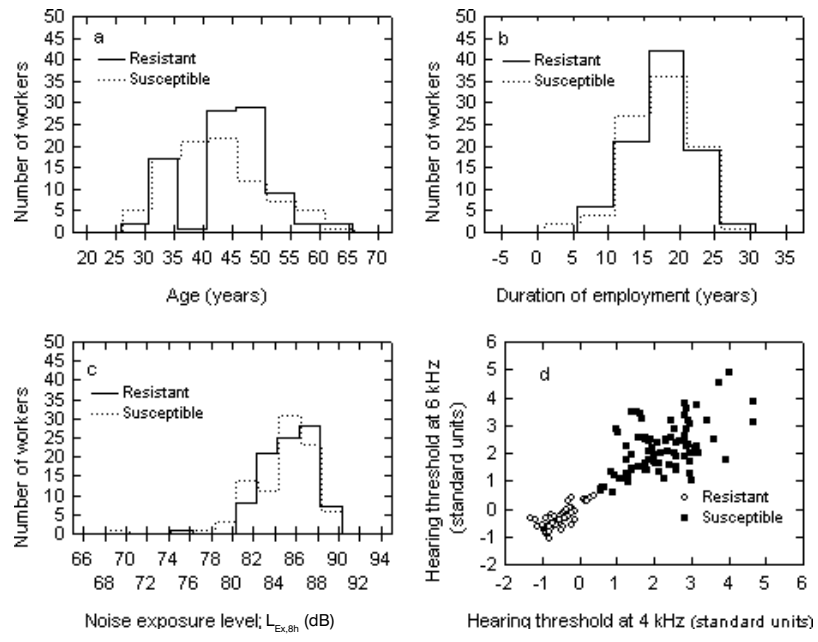

a) Age distribution in the noise-susceptible and noise resistant subgroups. The noise-susceptible subgroup is younger than the noise-resistant subgroup ( $p=0.0028)$; $b$ ) The duration of employment in the noise-susceptible and noise-resistant subgroups. There is no difference in the duration of employment between two subgroups $(p=0.64)$;

c) The noise exposure level (normalized to 8-h working day, averaged over total exposure time) in the noise-susceptible and noise-resistant subgroups. There is no difference in the noise exposure level between two subgroups ( $p=0.12)$; ) Standardized hearing thresholds in the noise-susceptible and noise-resistant subgroups. Note a very poor separation of hearing thresholds in both subgroups (with no gap between the susceptible and resistant subjects).

Fig. 5 Classification IV - eighteen subgroups divided by age, noise exposure level and duration of employment.

the ISO standard, while the audiometric curves of resistant subgroups overlap each other and lay between decile 0.5 and decile 0.9 (Fig. 6). For the subgroups of the workers classified as susceptible to noise, the poorest hearing thresholds were seen in classification I, while the best ones in classification IV. This suggests that classification I is most appropriate, while other classifications are less suitable to differentiate individuals for their vulnerability to noise.

\section{DISCUSSION}

The classification of noise-exposed subjects at the two extremes of the phenotypic spectrum, i.e., the workers who develop the greatest hearing loss due to a given exposure to noise (subjects susceptible to NIHL) and the workers who develop the lowest hearing loss after similar noise exposure (subjects resistant to NIHL) has a great advantage of much higher power for identifying underlying genes in the future genetic studies of NIHL susceptibility genes.

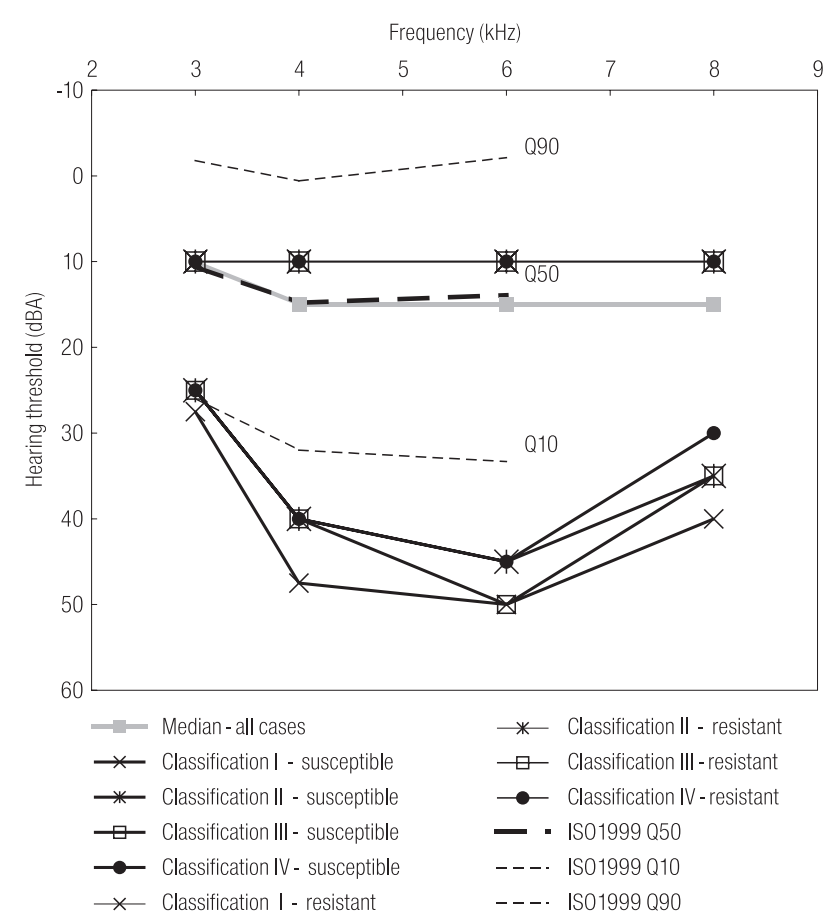

Fig. 6. Median hearing thresholds (in the frequency range of 3-8 kHz) in the resistant (thin solid lines, the selection curves overlap each other) and susceptible (thick solid lines) groups for different methods of workers' classification vs. median hearing thresholds (dashed lines, fractile 0.1, 0.5, and 0.9) predicted with the ISO 1999:1990 model for the entire study population.

ISO 1999:1990 is the most recent document prepared using a large database of nearly 7000 industrial workers [11]. It includes all the most crucial variables influencing hearing in humans, i.e., age, gender, duration of employment, and noise exposure level. It has been shown that database ISO A - with certain adjustments - could serve as a reference for the younger unscreened population [15]. Although being not perfect, it is now considered as a "gold standard" allowing to predict noise-induced permanent hearing threshold shift in a given worker and median hearing loss with fractiles in a given noise-exposed population.

In this study we used four methods for classifying noisesusceptibility of workers and compared the distribution of hearing thresholds (expressed in standard units, i.e., as the differences between hearing thresholds actually measured and those predicted from the ISO 1999:1990 document) in the susceptible and resistant groups of workers. We considered it advisable to shift apart hearing thresholds as a more reliable method of workers' classification. The population consisted of male subjects, with rather homo- 
geneous exposure to steady-state noise not exceeding the level of $91 \mathrm{~dB}(\mathrm{~A})$. Thus, age factor (presbyacusis), duration of employment and level of noise were the main variables influencing the hearing threshold.

In classification I ("gold standard" method), the hearing levels of $10 \%$ of susceptible workers and $10 \%$ of resistant ones were more than 1 standard unit apart. The susceptible group was significantly younger and exposed to noise for a shorter time. These findings are in line with the definition of increased vulnerability to NIHL [3]. The majority of susceptible subjects were exposed to noise at relatively low equivalent level (below $86 \mathrm{~dB}-\mathrm{A}$ ), and again, it is known that the most vulnerable ears develop hearing impairment at lower levels of noise, classified as being quite safe to hearing in the general population.

Every subsequent approach to classification tried to preeliminate the influence of the following factors: age (classification II), age and level of noise (classification III), and age, level of noise and duration of employment (classification IV). Although these classifications allowed to neglect between-group differences in mean values of age (classification II), mean values of duration of employment and level of noise (classification IV), and mean values of age, duration of employment and level of noise (classification III), the plots of hearing threshold levels expressed in standard units showed poorer segregation, with some overlapping cases in classification III. Also, the analysis of median HTLs of susceptible subjects showed the poorest values in classification I as compared to other classifications, suggesting that the first approach is most appropriate.

In the study by Carlsson et al. [18], the population of 1200 noise-exposed workers was investigated in Sweden. The selection of noise-susceptible and noise-resistant workers was based on audiometric analysis in nine subgroups, and followed by DNA sampling and analyzed with respect to the Connexin 26 (Cx26) 35 delG gene mutation. The subgroup categories were similar to those in our study (three age/tenure groups: $<35 / 10 \mathrm{yr}, 35-50 \mathrm{yr} / 20 \mathrm{yr},>50 \mathrm{yr} / 30 \mathrm{yr}$ and three noise exposure groups: $<85 \mathrm{dBA}, 86-91 \mathrm{dBA}$, $>92 \mathrm{dBA}$ ), except for noise exposure that in our study was never higher than $91 \mathrm{dBA}$. Another difference concerns the frequency used in the subject's selection -4 and $6 \mathrm{kHz}$ in our study, and $3 \mathrm{kHz}$ used by Carlsson et al. Although the authors showed a good agreement of audiometric curves for workers classified as susceptible to NIHL and the international ISO standard, in seven out of 9 susceptible subgroups, HTL audiometric curves laid above 0.1 fractile (between fractile 0.1 and 0.5 ), and in two groups only (middle age groups, low and moderate noise exposures) they were at, or below 0.1 fractile predicted with the ISO model. Also, an individual audiogram of the worker who was shown to be a carrier of $\mathrm{C} \times 2635 \mathrm{delG}$ gene mutation, was atypical as for NIHL. This could suggest that the pre-selection of workers (to age and exposure subgroups) and adoption of $3 \mathrm{kHz}$ as the reference frequency is not the most appropriate approach to workers' dichotomization and could possibly influence further genetic analysis. Based on the results of earlier studies, it has been concluded that permanent threshold shift in subjects exposed to noise resulted rather from ageing than from noise exposure [19]; particularly, if workers strictly followed the recommendation to use hearing protectors at work [4]. So, age might be a confounding factor in the selection of subjects according to their susceptibility to noise. On the other hand, the extent to which age and noise co-influence hearing is not critical with regard to searching for susceptibility genes, since, as shown in mice, the same genes seem to be responsible for age-related hearing loss and NIHL [20].

Although the ISO 1999:1990 model is commonly used as a reference method of hearing threshold prediction, it does not comprise risk factors other than age, gender and noise exposure. Other factors contributing to variation in vulnerability to noise include noise impulsiveness, leisure noise and military noise, exposure to some chemicals, smoking, ototoxic drugs uptake, elevated blood pressure and serum cholesterol, and the use of hearing protectors. Thus, the newer hearing conservation programs predict hearing loss by notifying risk factor to individuals. A good example is NoiseScan program, developed by Finnish researchers, that predicts hearing loss with ISO1999 in combination with weighting different individual risk factors [11].

The novel NoiseScan data management system enables to assess the risk of developing hearing impairment on the ba- 
sis of known risk factors. The study by Kuronen et al. [14] investigated the risk of hearing impairment among Finnish Air Force pilots using reasonably accurate noise exposure data and other risk factors for hearing impairment. It was further compared with that observed in industrial workers which followed the ISO 1999:1990 model of prediction. Hearing among Finnish military pilots turned out to be better than predicted by the ISO 1999:1990 model, and 9-13 $\mathrm{dB}$ better than in industrial workers. These findings were explained by a much larger number of risk factors in industrial workers than in pilots [14].

Noise impulsiveness is one of the most significant factors contributing to NIHL. The results of our previous study carried out in workers exposed to impulse noise and steady-state noise showed that at least $5-10 \mathrm{~dB}$ correcting factor should be added to hearing levels at high frequencies to adjust for the effect of noise impulsiveness [21]. It is not the case in this study, because all the workers were exposed to steady-state noise. Also, the same hearing conservation program was followed by all factory workers, thus eliminating the use of hearing protectors as a possible confounding factor.

The results of the studies on the correlation between tobacco smoking and hearing loss are inconsistent. Some studies have shown a significant association between these two variables, others have not [10]. The positive studies show that the frequencies affected are predominantly high frequencies. In this study population, the number of smokers in the susceptible and resistant subgroups did not differ significantly (data not shown), which confirmed that smoking was not a confounding factor in classification of subjects. There was no exposure to ototoxic chemicals (such as organic solvents) in the factory, and the prevalence of history of exposure to solvents did not differ between the subgroups. Less than $10 \%$ of workers reported an uptake of ototoxic drugs (aminoglycosides) in the past, and the percent of such individuals did not differ between susceptible and resistant subgroups. Other factors contributing to variation in vulnerability to noise were of lower influence on the hearing threshold or were relatively rare. Therefore, they could be disregarded in the workers' classification models to be used in further genetic studies.

\section{CONCLUSIONS}

Considering that the ISO 1990:1999 model is a reference method for the prediction of hearing level in the ageing, noise-exposed population, every other approach to the workers' classification into noise-susceptible and noiseresistant individuals leads to the worse hearing thresholds separation between these two subgroups. The selection of subjects from the entire worker population of a given industry based on the ISO 1999:1990 standard may be regarded as the most reliable method of classification of noise-susceptible and noise-resistant workers to be used in the future genetic studies on NIHL susceptibility genes.

\section{REFERENCES}

1. McReynolds MC. Noise-induced hearing loss. Air Med J 2005; 24(2):73-8.

2. Hellström PA, Dengerink H. The relevance of A-weighted sound pressure levels when predicting the risk for NIHL. In: Henderson D, Prasher D, Kopke R, Salvi R, Hamernik R, editors. Noise Induced Hearing Loss: Basic Mechanisms, Prevention and Control. London: NRN Publications; 2001. pp. 341-50.

3. Plontke S, Zenner Tübingen HP. Current aspects of hearing loss from occupational and leisure noise. In: Schultz-Coulon HJ, editors. Environmental and Occupational Health Disorders. Germany: Videel OHG; 2004. pp. 233-325.

4. Raynal M, Kossowski M, Job A. Hearing in military pilots: One-time audiometry in pilots of fighters, transports, and helicopters. Aviat Space Environ Med 2006;77(1):57-61.

5. Pyykkö I, Starck J, Toppila E, Ulfendahl M. Noise-induced hearing loss. In: Luxon L, Furman JM, Martini A, Stephens D, editors. Textbook of Audiological Medicine. Clinical Aspects of Hearing and Balance. London: Martin Dunitz, Taylor\&Francis Group; 2003. pp. 89-100.

6. Starck J, Toppila E, Pyykkö I. Impulse noise and risk criteria. Noise Health 2003;5(20):63-73.

7. Abbate C, Concetto G, Fortunato M, Brecciaroli R, Tringali MA, Beninato $\mathrm{G}$, et al. Influence of environmental factors on the evolution of industrial noise-induced hearing loss. Environ Monitor Assess 2005;107(1-3):351-61.

8. Henderson D, Subramaniam M, Boettcher FA. Individual susceptibility to noise-induced hearing loss: An old topic revisited. Ear Hear 1993;14(3):152-68.

9. Śliwińska-Kowalska M, Zamysłowska-Szmytke E, Szymczak W, Kotyło P, Fiszer M, Wesołowski W, et al. Exacerbation of noise-induced 
hearing loss by co-exposure to workplace chemicals. Environ Toxicol Pharmacol 2005;19:547-53.

10. Nomura K, Nakao M, Morimoto T. Effect of smoking on hearing loss: Quality assessment and meta-analysis. Prev Med 2005;40(2):138-44.

11. Pyykkö I, Starck J, Toppila E, Johnson A-C. Methodology and value of databases. In: Henderson D, Prasher D, Kopke R, Salvi R, Hamernik R, editors. Noise Induced Hearing Loss: Basic Mechanisms, Prevention and Control. London: NRN Publications; 2001. pp. 387-400.

12. Barrenas ML, Hellström PA. The effect of low level acoustic stimulation on susceptibility to noise in blue- and brown-eyed young human subjects. Ear Hear 1996;17(1):63-8.

13. ISO 1999:1990. Acoustics - Determination of Occupational Noise Exposure and Estimation of Noise-inducted Hearing Impairment. Geneva: International Committee for Standardization; 1990.

14. Kuronen P, Toppila E, Starck J, Paakkonen R, Sorri MJ. Modelling the risk of noise-induced hearing loss among military pilots. Int J Audiol 2004;43(2):79-84.

15. Borchgrevink HM, Tambs K, Hoffman HJ. The Nord-Tröndelag Norway audiometric survey 1996-98: Unscreened adult high-frequency thresholds, normative thresholds and noise-related socio-acusis. In: Henderson D, Prasher D, Kopke R, Salvi R, Hamernik R, editors.
Noise Induced Hearing Loss: Basic Mechanisms, Prevention and Control. London: NRN Publications; 2001. pp. 377-86.

16. ISO 8253-1:1998. Acoustics - Audiometric Test Methods - Part 1. Basic Pure Tone and Bone Audiometry. Geneva: International Committee for Standardization; 1998.

17. ISO 7029:2000. Acoustic - Statistical Distribution of Hearing Thresholds as a Function of Age. Geneva: International Committee for Standardization; 2000.

18. Carlsson P, Borg E, Grip L, Dahl N, Bondeson ML. Variability in noise susceptibility in Swedish population: The role of 35delG mutation in the connexin 26 (GJB2) gene. Audiol Med 2004;2(2):123-30.

19. Lee FS, Matthews LJ, Dubno JR, Mills JH. Longitudinal study of pure-tone thresholds in older persons. Ear Hear 2005;26(1):1-11.

20. Davis RR, Newlander JK, Ling X, Cortopassi GA, Krieg EF, Erway LC. Genetic basis for susceptibility to noise-induced hearing loss in mice. Hear Res 2001;155(1-2):82-90.

21. Pawlaczyk-Łuszczyńska M, Dudarewicz A, Zamysłowska-Szmytke E, Śliwińska-Kowalska M. Occupational exposure to noise, hand-arm vibration and organic solvents in dockyard and glass factory workers. In: Leventhall G, editors. Proceedings Low Frequency 2004, the 11th International Meeting on Low Frequency Noise and Vibration and its Control. Maastricht: MultiScience Publishing Co Ltd.; 2004. pp. 239-51. 